\title{
Green Automotive Industry: Global Trends and Challenges for Russian Car Manufacturers
}

\author{
Irina Krakovskaya ${ }^{1}$, Lyudmila Zhurova, ${ }^{2, *}$, and Anna Shekhtman ${ }^{3}$ \\ ${ }^{1}$ National Research Mordovia State University, Bolshevistskaya Str., 68/1, 430005 Saransk, Russia \\ ${ }^{2}$ Samara University of Public Administration «International Market Institute», 21 G.S. Aksacov Str., \\ 443030 Samara, Russia \\ ${ }^{3}$ Volzhsky University named after V.N. Tatishchev, Leningradskaya Str, 16, 445020 Togliatti, Russia
}

\begin{abstract}
The transition to the "green" model of the economy is a complex strategic task that requires a combination of two development vectors: maintaining dynamic economic growth and long-term preservation of the natural environment. One of the key directions for resolving existing environmental problems is associated with decarbonization and improving the eco-friendliness of vehicles. Almost all the world's automobile corporations are actively developing electric transport technologies and launching an increasing number of new models into mass production, offering alternative fuel sources. This paper investigates trends in the greening of the global automotive industry, the resulting threats and risks of the development of the national automotive industry, identifies the reasons for the environmental instability of the Russian automotive industry.
\end{abstract}

\section{Introduction}

Global climate change is recognized as one of the key challenges of the 21 st century. A climate agreement setting the goal of preventing temperatures from rising by more than $2^{\circ} \mathrm{C}$ (and, if possible, no higher than $1.5^{\circ} \mathrm{C}$ ) compared to the pre-industrial period was signed in Paris in December 2015. The Paris Agreement assigns a major role in reducing greenhouse gas emissions to states. Most states are responding to climate challenges and threats by moving to a sustainable development trajectory with low $\mathrm{CO}_{2}$ emissions.

In this regard, the issues of regulation of anthropogenic greenhouse gas emissions are being updated. The topic of carbon regulation for Russia has become particularly relevant after the EU plans to introduce a cross-border carbon levy. The potential losses of Russian exports from its actions may amount to up to 50 billion euros by 2030 [1].

Road transport makes a significant contribution to total $\mathrm{CO}_{2}$ emissions. For example, in $2019,18 \%$ of the world's $\mathrm{CO}_{2}$ emissions from fuel combustion were attributed to road transport [2]. In the EU, road transport accounts for $72.8 \%$ of greenhouse gas emissions, of which $44 \%$ are associated with passenger cars [3].

A global trend has become the active introduction of environmental standards that regulate the maximum emission standards for vehicles, which are constantly being tightened, primarily in the most economically developed countries. In 1988, Europe adopted the first

\footnotetext{
* Corresponding author: zhurova.1i@mail.ru
} 
standards for the emission of pollutants by cars, which were called Euro 0. This solution of environmental issues has reached a new level in the process of creating the European Union and currently the EU has the Euro 6 standard.

Russia is noticeably lagging behind Europe in improving the environmental situation with vehicle emissions. To date, all cars produced in and imported into Russia are required to meet the requirements of Euro 5.

Regulatory pressure on the automotive industry around the world is increasing every year, primarily in terms of requirements for the content of harmful substances in the exhaust gases of cars. In 2019, the European Union approved "The European Green Deal", an economic development strategy aimed at achieving carbon neutrality by 2050 . It is planned to reduce greenhouse gas emissions by at least $55 \%$ by 2030 [4].

Automotive corporations, along with restrictions, see new opportunities in global challenges: they are developing electric transport technologies and launching an increasing number of new models into serial production; develop unconventional fuels in the conditions of the still underdeveloped electric charging infrastructure.

The global economic crisis of 2020 has become a driver of strengthening the environmental component in the aid packages of many developed and a number of developing countries. The global COVID-19 pandemic has reinforced trends for greening the industry and accelerated the growth of the global electric vehicle market. Major car corporations have announced plans to increase the number of models and sales of electric vehicles.

The transformation processes taking place in the global automotive industry certainly affect the development of the Russian automotive industry. The aim of the work is to study trends in the greening of the global automotive industry in the context of the impact of the economic crisis of 2020, to assess the resulting threats and risks for the national automotive industry.

\section{Materials and methods}

The research materials used for the study include publications of Russian and foreign scientists, statistical data of the Federal State Statistics Service of the Russian Federation, materials and reports of rating and analytical agencies.

The automotive industry, which is based on globalized supply chains, has a large negative impact on the environment, both in the production of auto components and vehicles, and in the operation of the final product. The trends and problems of greening and innovative development of the automotive industry were investigated in their works by W. Wellbrock D. Ludin L. Röhrle at al.; C.R. Vaz T.R.S. Rauen A.G.R. Lezana; C. Köllner; K. Richa C. W. Babbitt G. Gaustad; R. Reinhardt I. Christodoulou B.A. García at al.; B. Kondratyev V. Popov G. Kedrova; Karlik E. M.

The article analyzes the development trends of the global automotive industry in the context of the impact of greening requirements, assesses the threats and opportunities of greening processes in the global automotive industry for the Russian automotive industry.

Statistics from the International Energy Agency (IEA) on the dynamics of the global fleet of electric vehicles, and data from the KPMG report on the countries' readiness to develop electric mobility were used to analyze the state and identify trends in the development of the automotive industry.

Statistical data from the Federal State Statistics Service of the Russian Federation, the analytical agency AUTOSTAT, regulations governing the development of the automotive industry, reports of the Ministry of Energy of the Russian Federation, etc. were used to assess the state of the vehicle fleet in Russia and trends in the development of eco-friendly modes of transport in the country. 
Statistical and analytical research methods are used when studying the dynamics and structure of indicators that characterize the processes of development of the automotive industry. The methods of monographic description, the abstract-logical method and system analysis were used when studying the opinions of scientists and in formulating the point of view and conclusions. The applied research methods made it possible to identify trends in the development of the Russian automotive industry in the context of global trends in stricter requirements for the eco-friendliness of motor vehicles, to detect threats and risks of reducing the competitive advantages of the domestic automotive industry, consideration of which allows to determine the key directions of the industry's development, adjust strategic programs and plans for its development.

\section{Results and discussion}

The constant tightening of environmental requirements for vehicles makes it necessary to improve the manufactured equipment, use technological advances in electronics, communications and design, introduce eco-innovations aimed at reducing carbon dioxide and nitrogen oxide emissions, energy conservation and the development of alternative fuels [5].

One of the promising areas in the production of eco-friendly modes of transport is the production of electric vehicles, which is actively developing. In 2015, the world vehicle fleet (electric vehicles, buses and trucks) amounted to only 1.5 million units, and in 2019 it increased to 8.1 million units. The global pandemic reinforces trends in the greening of the automotive industry and accelerates the growth of the global electric vehicle market. The fleet of electric vehicles amounted to $11.3 \mathrm{mln}$. units (Table 1) at the end of 2020.

Table 1. World electric vehicle fleet by region, mln. units.

\begin{tabular}{|l|c|c|c|c|c|c|}
\hline \multicolumn{1}{|c|}{ Region } & $\mathbf{2 0 1 5}$ & $\mathbf{2 0 1 6}$ & $\mathbf{2 0 1 7}$ & $\mathbf{2 0 1 8}$ & $\mathbf{2 0 1 9}$ & $\mathbf{2 0 2 0}$ \\
\hline China & 0.5 & 0.9 & 1.7 & 2.9 & 4.1 & 5.4 \\
\hline Europe & 0.4 & 0.6 & 0.9 & 1.3 & 1.9 & 3.3 \\
\hline USA & 0.4 & 0.6 & 0.8 & 1.1 & 1.5 & 1.8 \\
\hline Other countries & 0.2 & 0.2 & 0.3 & 0.5 & 0.6 & 0.8 \\
\hline Total & 1.5 & 2.3 & 3.7 & 5.8 & 8.1 & 11.3 \\
\hline
\end{tabular}

Source: [6].

Despite a $16 \%$ decline in global car sales in 2020 , sales of electric vehicles increased by $41 \%$. The growth in sales was due to the implementation of government incentive programs for the purchase of electric vehicles. Governments around the world spent $\$ 14$ billion (25\% more than in 2019) to support sales of electric vehicles. Also, the growth of sales is influenced by the expansion of the model range of electric vehicles, the development of charging infrastructure, the reduction in the cost of batteries and, as a result, the cost of electric vehicles.

Major car corporations announce plans to increase the number of models and sales of electric vehicles. At the same time, a number of automakers plan to reconfigure their production lines for the production of electric vehicles only: Volvo announced its decision to sell only electric vehicles from 2030, General Motors - from 2035; Stellantis targets $70 \%$ of electric vehicle sales in Europe and $35 \%$ in the US; Volkswagen targets $70 \%$ of electric vehicle sales in Europe and 50\% in China and the US by 2030 [6].

Definitely, the shift towards electric mobility will affect suppliers of automotive components and will require a review of supply chains [7].

According to IEA forecasts, the global electric vehicle fleet in 2030 may reach 230 million units, which will amount to $12 \%$ of the vehicle fleet [6]. 
However, in addition to the positive contribution of electric vehicles to solving the problems of greening, it is necessary to note a number of negative aspects related, in particular, to the production and disposal of batteries. Lithium-ion batteries require scarce non-renewable raw materials (for example, cobalt and lithium), which are often mined under critical conditions, which entails social and environmental problems [8, 9]. In addition, today there is no perfect technology for the disposal of batteries (there are developments concerning the recovery and reuse of batteries in electric vehicles [10], reprofiling and further use in stationary battery energy storage systems $[11,12]$ (for example, Tesla and Nissan follow the latter trend), but the cost of battery disposal is still very high.

Another problem is how the electricity used to charge the batteries is generated. Despite the development of renewable energy sources, most of the electricity is generated from fossil energy, which also negatively affects the environment [13].

Solving the above-mentioned problems remains the key task of greening the automotive industry.

Russia lags far behind other countries in terms of readiness to use technologies for the production of electric vehicles. Russia took 26th place in the KPMG rating of 30 countries 2020 Electric Vehicle Readiness Index [14]. The fleet of electric vehicles in Russia as of January 01,2021 , amounted to over 10.8 thousand units (a significant part of which are used electric vehicles) [15]. The main reasons for the weak development of the electric vehicle market are the lack of local modern developments in the field of light electric vehicles, the lack of proper charging infrastructure, government stimulation of consumer demand, and high prices for electric vehicles. Another important factor hindering the sale of electric vehicles in Russia is the need to travel long distances, which requires periodic recharging of the batteries. In addition, the operating temperature of lithium-ion batteries, which are equipped with electric vehicles, ranges from $0^{\circ}$ to $30^{\circ}$; part of the energy is lost at low temperatures.

Taking into account the increased competition in the electric car markets in developed countries and China, global automobile corporations are beginning to consider the Russian market as a promising one. So, on April 19, 2021, Volkswagen Corporation announced plans to develop business in the field of electric vehicles in Russia, the corporation intends to develop a service infrastructure for the repair and maintenance of electric vehicles in the country. The corporation started the cooperation with Rosseti PJSC for the development of the charging infrastructure [16].

The Ford Corporation plans to begin serial production of the Ford Transit electric van in Russia in 2022. Production will be launched in parallel with the main diesel platform of the truck at the Ford Sollers enterprise [17]. But the use of such vans will be limited by the largest cities with the highest population density and volumes of intracity logistics.

The main problem of ensuring the eco-friendliness of vehicles in Russia is a high proportion of the outdated fleet of vehicles. As of January 01, 2021, the Russian vehicle fleet reached 60 million units, the overwhelming share of it (76\%) is occupied by cars ( 45 million units). The average age of the Russian car fleet as of January 01, 2021, was 15.2 years. At the same time, the average age of passenger cars was 13.9 years (more than $40 \%$ of them are younger than 10 years), light commercial vehicles - 15.9 years, trucks - 21.6 years, buses 16.6 years [18]. For comparison, the average age of cars in the EU is 11.5 years [19].

As of January $01,2021,58.7 \%$ of the Russian freight fleet, $39.2 \%$ of buses, $38.3 \%$ of LCVs, and $24.2 \%$ of passenger cars did not even comply with Euro-2 standards (Table 2). 
Table 2. The share of the Russian vehicle fleet in terms of toxicity standards (as of January 01, 2021), $\%$.

\begin{tabular}{|l|c|c|c|c|}
\hline Standards & $\begin{array}{c}\text { Passenger } \\
\text { cars }\end{array}$ & $\begin{array}{c}\text { Light } \\
\text { commercial } \\
\text { vehicles }\end{array}$ & Trucks & Buses \\
\hline Below Euro-2 & 24.2 & 38.3 & 58.7 & 39.2 \\
\hline Euro-2 & 11.3 & 15.5 & 8.5 & 11.6 \\
\hline Euro-3 and & 14.0 & 15.2 & 10.8 & 23.4 \\
\hline Euro-4 & 22.5 & 8.0 & 14.0 & 22.3 \\
\hline $\begin{array}{l}\text { Euro-5 } \\
\text { above }\end{array}$ & & 8.0 & 3.5 \\
\hline
\end{tabular}

Source: compiled from [18].

An urgent task for large cities is the renewal of electric transport. According to Rosstat data, the share of the fleet of tram cars and trolleybuses in operation over 25 years old was $59 \%$ and $22 \%$, respectively, at the end of 2019 . The fleet of tram cars and trolleybuses under the age of 5 years includes only $11 \%$ [20]. Currently, projects in the field of development and production of electric buses are being implemented in Russia (this segment includes the KAMAZ Group, the GAZ Group and the Bakulin Motors Group holding with the Volgabus project, which have launched mass production). The annual production of electric buses exceeds 300 units [21].

In May 2021, the Ministry of Economy formed the first parameters of the concept for the development of electric transport in Russia. The government has set goals to increase the share of electric vehicles from $0.1 \%$ to $15 \%$ of the market in 2030 . Total expenditures for the implementation of this goal are planned in the amount of 418 billion rubles (including 153.5 billion rubles from the federal budget and extra-budgetary funds). In parallel, it is planned to restrict the import of electric vehicles and localize the production of batteries and engines [22]. So, in March 2021, Russia and other countries of the European Economic Community (EEC) have already decided not to extend the privileges on the import of electric vehicles. The import duty will be $15 \%$ of the customs value of the vehicle starting from 2022 .

The priority direction of the domestic automotive industry development, which Russia relies on, is to increase the eco-friendliness of vehicles through the use of gas-engine fuel. It is assumed that the volume of production of vehicles using natural gas as a motor fuel by 2025 will amount to $12-14$ thousand units (of which about $65 \%$ are buses, $35 \%$ are commercial vehicles) [23]. However, the lack of automobile gas-filling compressor stations is a limiting factor in the growth of the market and the prospects for decarbonization of the industry.

We can note that the priority of natural gas as a promising environmentally friendly motor fuel is obvious for many countries of the world. In many countries of the world (for example, the United States, Canada, Italy, etc.), there are national programs for converting vehicles, primarily urban vehicles, to gas-powered fuel.

Table 3 shows the dynamics of vehicles with the ability to use natural gas as a motor fuel.

Table 3. The number of vehicles that can use natural gas as a motor fuel (at the end of the year).

\begin{tabular}{|c|c|c|c|c|}
\hline Vehicle types & 2015 & 2017 & 2018 & 2019 \\
\hline \multicolumn{5}{|c|}{ Total number of registered vehicles, thousand units. } \\
\hline Passenger cars & 44253 & 46887 & 47425 & 48400 \\
\hline Trucks & 6230 & 6434 & 6490 & 6540 \\
\hline
\end{tabular}


Table 3. Ccontinued

\begin{tabular}{|l|c|c|c|c|}
\hline Buses & 873 & 896 & 864 & 869 \\
\hline \multicolumn{5}{|c|}{ The number of vehicles that can use natural gas as a motor fuel, thousand units. } \\
\hline Passenger cars & 956 & 1027 & 982 & 1036 \\
\hline Trucks & 375 & 406 & 377 & 390 \\
\hline Buses & 66 & 80 & 69 & 72 \\
\hline \multicolumn{7}{|c|}{ Share of vehicles that can use natural gas as a motor fuel, in the total number of } \\
registered vehicles, \%* & 2.2 & 2.2 & 2.1 & 2.1 \\
\hline Passenger cars & 6.0 & 6.3 & 5.8 & 6.0 \\
\hline Trucks & 7.6 & 8.9 & 8.0 & 8.3 \\
\hline Buses &
\end{tabular}

Source: compiled from [20].

* authors' calculations

The program of updating the fleet for gas-powered vehicles has been implemented since 2014. As Table 3 shows, the number of vehicles using natural gas as a vehicle fuel increased in 2019. Since 2019, a program has been implemented to subsidize the costs of converting equipment to use natural gas as motor fuel. Manufacturers of natural gas vehicles (AVTOVAZ Group, GAZ Group, UAZ) receive subsidies from the federal budget to compensate for the discount provided to customers [24].

In 2020, the number of produced vehicles that can use natural gas as a motor fuel was 6,185 units, and 10,677 units were re-equipped to use natural gas as a motor fuel [25]. Within the state program "Development of Energy" in 2020-2024, it is envisaged to allocate more than 19 billion rubles to co-finance the construction of gas filling infrastructure facilities (CNG filling stations and cryo-filling stations), re-equip the existing automobile equipment for the use of gas engine fuel [26].

However, it should be noted that natural gas, although a more eco-friendly form of motor fuel than diesel and gasoline, is nevertheless not a renewable source of energy, in addition, there are certain technical and economic problems of using natural gas as a motor fuel (difficulties when starting a cold internal combustion engine at low ambient temperatures, the high cost of re-equipping a car, etc.) [27].

Thus, each of the energy sources has its own advantages and disadvantages, and each technology can occupy its own niche in the field of road transport, so it is necessary to develop all directions in parallel.

\section{Conclusion}

1. Global trends in the field of greening and innovative development set the benchmarks for the development of the domestic automotive industry. Environmental requirements for automotive products on the part of states will be tightened further, which will certainly have a negative impact on the competitiveness and market prospects of automotive corporations that are not engaged in the development and production of eco-friendly cars. The main reasons for the weak development of the electric vehicle market are the lack of local modern developments in the field of light electric vehicles, the lack of proper charging infrastructure, government stimulation of consumer demand, and high prices for electric vehicles.

2. The global market for eco-friendly vehicles (primarily electric) will grow steadily, reducing the ability to manufacture and export traditional vehicles. Russia lags far behind from other countries in its readiness to use innovative technologies in the automotive industry, which threatens to lose the market for domestic automotive corporations. In this 
regard, it is necessary to update the existing strategies and programs for the development of the automotive industry in Russia, coordinate state, sectoral, regional, cluster, and corporate strategic programs and projects in the field of the development of electric transport and the production of vehicles using natural gas as a motor fuel, ensuring the effective achievement of the goals of sustainable development of the industry and the transition to carbon neutrality of the transport complex.

3. State support for the development of the eco-friendly cars market should be aimed not only at stimulating the manufacturers of such cars but also at stimulating demand for them. Also, the state policy should be aimed at increasing the localization of automotive components, the development of the domestic electronic industry to reduce import dependence and increase the share in the formation of added value in the production of eco-friendly cars.

4. The development of markets for eco-friendly electric vehicles at the global and national levels is possible only subject to dealing with issues associated with the revision of supply chains, the greening of production and disposal of lithium-ion batteries, the transition from the use of fossil energy to renewable energy sources. In turn, the growing requirements for automakers to minimize their carbon footprint will lead to tougher environmental requirements for suppliers of automotive components, logistics and other services.

\section{References}

1. VestiRU economy, https://www.vesti.ru

2. Tracking Transport 2020, https://www.iea.org

3. M. Damert, F. Rudolph, Policy Options for a Decarbonization of Passenger Cars in the EU (2018)

4. The European Commission, https://ec.europa.eu

5. W. Wellbrock, D. Ludin, L. Röhrle, at al. Int J. Corporate Soc. Responsibility, 5, 10 (2020)

6. Global EV Outlook 2021, https://www.iea.org

7. V. Kondratyev, V. Popov, G. Kedrova, World Economy and International Relations, 64(3), 68 (2020)

8. C. Köllner, ATZ Elektron, 13, 8 (2018)

9. H. Haase, F. Koerner, H. Strubelt, Climate Adaptation and Sustainability, https://www. ilm.ovgu.de

10. K. Richa, C. W. Babbitt, G. Gaustad, J. Ind. Ecol., 21(3), 715 (2017)

11. R. Reinhardt, I. Christodoulou, B. A. García, S. Gassó-Domingo, J. Clean. Prod., 254 (2020)

12. N. Jiao, S. Evans, Smart Innov. Syst. Technol., 68, 537 (2017)

13. I. Vlasova, Lack of energy: why there are no electric cars in Russia (2020)

14. KPMG, https://assets.kpmg

15. AUTOSTAT, https://www.autostat.ru

16. Tadviser, https://www.tadviser.ru

17. Vedomosti, https://www.vedomosti.ru

18. AUTOSTAT-RADAR, https://rim3.ru

19. Acea - European Automobile Manufacturers' Association, https://www.acea.be

20. Federal State Statistics Service, https://gks.ru 
21. D.V. Sanatov, et al., Prospects for the development of the market for electric transport and charging infrastructure in Russia: expert and analytical report (2021)

22. Kommersant, https://www.kommersant.ru

23. The strategy for the Russian automotive industry development for the period up to 2025 (approved by the Order of the Government of the Russian Federation dated April 28, 2018, No. 831-r) (revised on February 22, 2019, No. 263-r)

24. Resolution of the Government of the Russian Federation dated May 13, 2020, No. 669 (revised on February 04, 2021) "On Approval of the Rules for the Provision of Subsidies From the Federal Budget to Manufacturers of Equipment That Uses Natural Gas as a Motor Fuel"

25. Report on the implementation of the state program "Energy Development", Ministry of Energy of the Russian Federation (2021)

26. Resolution of the Government of the Russian Federation dated April 15, 2014, No. 321 (revised on March 31, 2021) "On Approval of the State Program of the Russian Federation "Energy Development"

27. E. M. Karlik, Economic Sciences, 3(148), 30 (2017) 